Board of Governors of the Federal Reserve System

International Finance Discussion Papers

Number 537

January 1996

\title{
USING MEASURES OF EXPECTATIONS TO IDENTIFY THE EFFECTS OF A MONETARY POLICY SHOCK
}

Allan D. Brunner

NOTE: International Finance Discussion Papers are preliminary materials circulated to stimulate discussion and critical comment. References in publications to International Finance Discussion Papers (other than an acknowledgement that the writer had access to unpublished material) should be cleared with the author or authors. 


\begin{abstract}
This paper considers an altemative econometric approach to the VAR methodology for identifying and estimating the effects of monetary policy shocks. The alternative approach incorporates available measures of market participants' expectations of economic variables in order to calculate economic innovations to those variables. In general, expectations measures should provide important additional information relative to a standard VAR analysis, since market participants presumably use a much richer information set than that assumed in a typical VAR model. The resulting innovations are easily incorporated in a VAR-like framework.

The empirical results are quite surprising. First, when expectations are incorporated, the variance of all innovations is reduced substantially. Second, innovations to the federal funds rate derived using the alternative approach are only somewhat correlated with their VAR counterparts, while innovations to other economic variables are essentially uncorrelated. Still, monetary policy shocks derived using the two approaches are also somewhat correlated, since innovations to prices and economic activity explain only a small fraction of innovations to the federal funds rate. As a consequence, the impulse responses of economic variables to the two sets of monetary policy shocks have remarkably similar properties.
\end{abstract}




\title{
Üsing Measures of Expectations to İdentify the Effects of a Monetary Policy Shock
}

\author{
Allan D. Brunner ${ }^{1}$
}

\section{Introduction}

Vector autoregressive (VAR) models, popularized by Sims (1980), have been used widely and extensively by economists to study the dynamic behavior of economic variables. The appeal of VAR models is likely due to several attractive features relative to other econometric modeling approaches. These features include a minimum number of identifying restrictions, few exogenous variables, and an ease of implementation. Still, the use of a VAR model requires a few strong assumptions about the availability of information to economic agents, some of which are also common to other moreoveridentified econometric models. This paper considers an alternative approach that address some possible shortcomings of the VAR approach, while maintaining many of its appealing features.

The estimation of a structural VAR m-iel generally requires two steps. First, a vector of economic variables, $X_{t}$, is regressed on several lags of itself. The set of lagged variables (dated $t-1$ and earlier) is assumed to be a good proxy for the information set that is available to economic agents just prior to the determination of $\mathrm{X}_{\mathrm{t}}$. As a consequence, VAR residuals are interpreted as economic innovations, new information about $\mathrm{X}_{\mathrm{t}}$ that becomes available at time $\mathrm{t}$. In the second step of estimation, the innovations are decomposed into orthogonal shocks using one of several methods. These shocks are often given a structural or behavioral interpretation.

This paper is concerned primarily with two implicit assumptions that are made in the first step

1 The author is an economist in the International Finance Division, Board of Governors of the Federal Reserve System. The author would like to thank Neil Ericsson, Bill Helkie, Dale Henderson, and workshop participants at the Board of Governors for useful comments on earlier versions of this paper. He is aiso grateful to Larry Christiano, Charlie Evans, Christian Gilles, Vincent Reinhart, and Glenn Rudebusch for helpful discussions and to Athanasios Orphanides and James Walsh for providing the MMS data. This paper represents the views of the author and should not be interpreted as reflecting the views of the Board of Governors of the Federal Reserve System or other member of its staff. The author is responsible for any errors. 
of the VAR methodology that may not accord well with reality. First, since many economic data for a particular period are not released until subsequent periods, the information set that is typically used by VAR models contains information that is not yet available to some economic agents. Second, there is an assumption that the appropriate information set contains only lagged values of $\mathrm{X}_{\mathrm{t}}$. In actuality, the correct information set likely contains lags of many other economic variables not contained in $\mathrm{X}_{\mathrm{t}}$.

In this paper, the first problem is addressed by simply dropping from the information set those data that are not actually available to economic agents. The second problem is mitigated by incorporating market participants' expectations of economic variables. These expectations measures should bring important additional information into the analysis, since market participants presumably use a much richer information set (relative to a standard VAR model) to make their forecasts. Importantly, the expectations measures serve as an efficient and convenient way to expand the implied information set beyond that used by a typical VAR model.

In order to illustrate the alternative econometric methodology, this paper considers the task of identifying monetary policy shocks and estimating their effects on various macroeconomic variables. Indeed, there has been a great deal of recent interest in this topic. For example, Christiano and Eichenbaum (1992) and Leeper and Gordon (1992) examined the "liquidity effects" of monetary policy shocks, the immediate reaction of economic variables to unexpected changes in the stance of monetary policy. More recently, Bemanke and Blinder (1992), Strongin (1992), Gordon and Leeper (1995), Christiano, Eichenbaum, and Evans (1994) and Brunner (1994) have explored alternative ways of identifying monetary policy shocks and tracing out their effects on the macroeconomy. Importantly, much of this research was conducted using vector-autoregressive (VAR) models.

The empirical results are quite surprising. First, when expectations are incorporated, the variance of all innovations is reduced substantially. Second, innovations to the federal funds rate using the two methodologies -- using a VAR model and using market expectations -- are only 
somewhat correlated. The correlation between the two is .56 -- enough so that the VAR approach cannot be rejected out of hand, but not so large that the approach is validated. Innovations to other economic variables (prices and indicators of economic activity) are essentially uncorrelated. Still, monetary policy shocks derived using the two approaches are also somewhat correlated, since innovations to prices and economic activity explain only a smail fraction of innovations to the federal funds rate. As a consequence, the impulse responses of economic variables to the two sets of monetary policy shock have remarkably similar properties.

The remainder of the paper proceeds as follows. Section II demonstrates how the VAR methodology can be replaced with an altemative approach that incorporates measures of expectations. Section III examines whether selected measures of market expectations are, in fact, accurate predictions of actual economic outcomes. It also compares economic innovations calculated with both the VAR and alternative approaches. Similarly, section IV computes structural shocks using both methods, and it examines their effects on several economic variables. Section $V$ provides some concluding remarks.

\section{Using Measures of Expectations}

This section has two objectives. The first objective is to review the traditional VAR approach, popularized by Sims (1980), and to describe some potential problems with that modeling strategy. The second objective is to outline an alternative approach that addresses the possible shortcomings of the VAR approach. The main advantage of the alternative approach is that in incorporates measures of market participants' expectations in the estimation of economic innovations, while maintaining many of the appealing features of the VAR modeling strategy. This approach is illustrated by outlining the necessary steps to identify monetary policy shocks and to trace out their effects on selected economic variables. This particular application is pursued further in subsequent sections of the paper. 


\section{The VAR Approach}

Suppose that an economist is interested in studying the dynamic behavior of an $\mathrm{nxl}$ vector of economic variables, $X_{r}$. One modeling strategy is to estimate a structural VAR(p) model of $X_{t}$ :

$$
A_{0} X_{t}=\mu+A(L) X_{t-1}+\eta_{t}
$$

where $\mu$ is an $n x 1$ vector, $A(L)=A_{1}+A_{2} L+\ldots+A_{p} L^{p-1}, A_{i}$ is an nxn matrix, $L$ is the lag operator, and $\eta_{t}$ is a $\mathrm{nxl}$ vector of structural (orthogonal) shocks.

The estimation of a structural VAR model generally requires two steps. The first step is to estimate the reduced-form representation of $X_{t}$, where $X_{t}$ is regressed on $p$ lags of itself:

$$
X_{t}=\mu^{\prime}+B(L) X_{t-1}+u_{t}
$$

where $\mu^{\prime}$ is an $n \times l$ vector, $B(L)=B_{1}+B_{2} L+\ldots+B_{p} L^{p-1}, B_{i}$ is an nxn matrix, and $u_{t}$ is a nxl vector containing the reduced-form VAR innovations. Note that, by assumption, $u_{t}$ contains all new information about $X_{t}$ that becomes available during period $t$, and the only new information that is obtained during period $\mathrm{t}$ is about variables dated at time $\mathrm{t}$.

In the second step, the VAR innovations $\left(u_{t}\right)$ are used to estimate $A_{0}$ and to recover the structural shocks $\left(\eta_{\mathfrak{l}}\right)$. Equating equations (1) and (2) implies the following relationship between the reduced-form innovations and the structural shocks:

$$
A_{0} u_{t}=\eta_{t}
$$

In order for $A_{0}$ and $\eta_{t}$ to be identified, $A_{0}$ must contain at least $n(n-1) / 2$ zero-restrictions. Sims (1980) assumed that $A_{0}$ was lower-triangular in order to orthogonalize the innovations. With this assumption, $A_{0}$ and the $\eta s$ can be estimated with OLS, simply by regressing each innovation on other approp̣riate inñovations. In coñtrast̂t, Sims (1986) and Bernanke (1986) considered aiternative 
decompositions, where sufficient zero-restrictions were imposed on $A_{0}$ based on economic theory. In this case, more sophisticated estimation methods, such as instrumental variables or maximum likelihood are required. ${ }^{2}$

Once $A_{0}$ and the $\eta s$ have been estimated, the remaining structural parameters are calculated by observing that equations (1) and (2) also imply $A_{i}=A_{0}{ }^{-1} B_{i}(i=1, \ldots p)$. The structural model can then be used to study the time-series properties of the data in a number of ways. Often economists are interested in examining impulse response functions, which capture the dynamic responses of $\mathrm{X}_{\mathrm{t}}$ to the set of structural shocks $(\eta)$. The impulse response functions can be obtained by inverting the VAR, yielding the vector-moving-average (VMA) representation:

$$
\begin{aligned}
X_{t} & =\left[A_{0}-A(L)\right]^{-1} \mu+\left[A_{0}-A(L)\right]^{-1} \eta_{t} \\
& =\quad \mu^{\prime \prime}+C(L) \eta_{t}
\end{aligned}
$$

where $\mu$ "' is an $\mathrm{nxl}$ vector, $\mathrm{C}(\mathrm{L})=\mathrm{C}_{0}+\mathrm{C}_{1} \mathrm{~L}+\ldots$, and $\mathrm{C}_{\mathrm{i}}$ is an nxn matrix. The impulse response of any element of $X_{t}$ to a particular structural shock corresponds to the appropriate elements of $C(L)$. In addition, the VMA representation can also be used to decompose the forecast errors or the variance of $X_{t}$ into components attributable to individual elements of $\eta_{t}$.

There are a number of attractive features of the VAR methodology that have led to its popularity. First, the identification of the structural VAR model in equation (1) is achieved with a minimum number of identifying restrictions. Indeed, restrictions are often placed only on $A_{0}$, leaving $A(L)$ unrestricted. In contrast, other structural approaches often involve large numbers of restrictions on $A(L)$ that are often not tested and that may or may not be guided by economic theory. Since the parameters of a VAR model are relatively unconstrained, some economists consider a VAR model to

2 See Blanchard and Quah (1989) for an alternative identification scheme that places restrictions on the long-run effects of $\eta_{t}$. 
be a relatively atheoretical approach, allowing for a (possibly) richer set of dynamics than a moreoveridentified model would allow.

Second, there are often no exogenous variables in the VAR model other than constants, seasonal dummies, and deterministic time trends. As a consequence, the emphasis is placed on the effects of structural disturbances within the context of a fully-articulated system of endogenous variables, rather than on the effects of certain economic variables (endogenous or exogenous) on other variables. Finally, since each structural equation in the VAR model is treated symmetrically with respect to explanatory variables, the VAR methodology is easily and quickly implemented, often with only a few lines of computer code.

\section{Potential Problems with VARs}

The estimation of $A_{0}$ and $\eta_{t}$ in equation (3) depends critically on estimates of the VAR innovations $\left(u_{t}\right)$, the "first-stage" regressions shown in equation (2). There are at least two reasons why the VAR innovations in equations (2) may be poor proxies for the true innovations to $X_{t}$. First, there is good reason to believe that the information set implied by a typical VAR contains information that is not yet available to economic agents. For example, the VAR methodology assumes that all lagged values of $\mathrm{X}_{\mathrm{t}}$ are publicly observable at the end of period $\mathrm{t}-1$. Unfortunately, most economic data for a particular period are not available until subsequent periods and may be subject to revisions for months, weeks, or even years after their initial release. As a consequence, if some variables on the right-hand side of the regression in equation (2) are not actually observable at time $t-1$, the innovations will be improperly estimated.

Similarly, the VAR methodology assumes that the set of information available to economic agents at time $t-1$ contains only lags of $X_{r}$. In all likelihood, the appropriate information set is much richer than the one implied by a typical VAR model. If there exists additional information at time $t-1$ that helps predict $X_{1}$ and that is omitted from the regression in equation (2), the resulting estimated 
innovations are not true innovations and are inappropriate for identifying structural shocks to $\mathrm{X}_{\mathrm{t}}$.

Importantly, either of these two problems can be overcome with proper modifications to the structural VAR in equation (1). In the first case, the structural model could be constructed so that only information that is actually available is used as an explanatory variable. In the second case, $X_{t}$ could be expanded to include any necessary additional explanatory variables. Unfortunately, increasing the dimensions of $\mathrm{X}_{\mathrm{t}}$ is often undesirable or simply infeasible. Since even small VAR models typically require the estimation of a large number of parameters, adding more variables to the VAR system would only further exacerbate any problems with few degrees-of-freedom.

\section{An Alternative Approach}

This paper considers an alternative econometric approach to the VAR methodology that attempts to gauge the importance of the shortcomings described above. First, the problem of assuming too much in agents' information set is addressed by reconstructing $X_{t}$ so that only information that is actually known at time $t-1$ is used to calculate innovations. Second, the problem of excluding information that agents do have available is addressed by including available measures of market expectations in the estimation of economic innovations. These measures serve as a convenient and efficient way to include all relevant information necessary to calculate innovations.

In order to illustrate the alternative approach, consider the task of identifying monetary policy shocks and of tracing out their effects on various economic variables of interest $\left(\mathrm{X}_{\mathrm{t}}\right)$. Suppose that the Federal Reserve's policy instrument is the federal funds rate -- one of the variables in $\mathrm{X}_{\mathbf{1}}$-- and that the Fed's reaction function -- analogous to one of the structural equations in equation (1) -- can be written as follows:

$$
F F R_{t}=\phi+\gamma\left[X_{1, \ell}^{\prime} X_{2, t-1}^{\prime}\right]^{\prime}+\ldots+\eta_{1}^{M P}
$$

where $\phi$ is a constant, $\gamma$ is a $\mathrm{nxl}$ vector, $\mathrm{X}_{1, \mathrm{t}}$ is a vector of variables describing period $\mathrm{t}$ and observable 
at time $t, X_{2, t}$ is a vector of variables describing period $t$ and observable at time $t+1$, and $\eta^{M P}$, denotes a monetary policy shock. Note that with this specification, the federal funds rate responds contemporaneously to new information about $X_{1, t}$ and $X_{2, t-1}$. Finally, $\gamma$ contains some zero elements for identification purposes, analogous to the zero-restrictions on $\mathrm{A}_{0}$.

As with the VAR methodology, the first step is to calculate innovations to the federal funds rate, $X_{1,1}$ and $X_{2,1-1}$ :

$$
\begin{gathered}
F F R_{t}=\alpha_{1}+\beta_{i}(L)\left[X_{1, t-1}^{\prime} X_{2, t-2}^{\prime}\right]^{\prime}+\delta_{1} E\left[F F R_{t} \mid \hat{I}_{t-1}\right]+u_{t}^{F F R} \\
X_{1, t}=\alpha_{2}+\beta_{2}(L)\left[X_{1, t-1}^{\prime} X_{2, t-2}^{\prime}\right]^{\prime}+\delta_{2} E\left[X_{1, t} \mid \hat{I}_{t-1}\right]+u_{t}^{X 1} \\
X_{2, t-1}=\alpha_{3}+\beta_{3}(L)\left[X_{1, t-1}^{\prime} X_{2, t-2}^{\prime}\right]^{\prime}+\delta_{3} E\left[X_{2, t-1} \mid \hat{I}_{t-1}\right]+u_{t}^{X 2}
\end{gathered}
$$

where $\beta_{i}(L)$ is a matrix polynomial, $E\left[\cdot \mid \hat{I}_{t-1}\right]$ represents an observable measure of market participants' expectations of a particular variable, and $\hat{\mathrm{T}}_{t-1}$ is an unobservable information set that is implied by the observed expectations measure. There are a few interesting aspects of equation (6) that are worth discussing. First, it could be the case that using only lags of $\mathrm{X}_{1, t}$ and $\mathrm{X}_{2, t-1}$ are required to calculate innovations to the federal funds rate, to $X_{1, t}$ and to $X_{2, t-1}$. That is, the inclusion of the expectations measures adds no additional explanatory power to the regressions in equation (6). This possibility corresponds to the testable hypothesis that $\delta_{i}$ is equal to zero. On the other hand, it could be the case that market participants' forecasts of these variables are unbiased and efficient. That is, including the expectations measures in the regressions in equation (6) actually preclude using lags of other variables, if market participants use all useful information to make their forecasts. This possibility corresponds to the testable hypotheses that $\delta_{i}$ is equal to one (a test of unbiasedness) and that $\beta_{i}(\mathrm{~L})$ are equal to zero (a test of efficiency). 
In the second step of the alternative approach, innovations to the federal funds rate are regressed on innovations to all necessary variables in the Fed's reaction function:

$$
u_{t}^{F F R}=\gamma_{1} u_{t}^{X 1}+\gamma_{2} u_{t}^{X 2}+\eta_{t}^{M P}
$$

Analogous to equation (3) for the VAR approach, the regression in equation (7) yields a set of structural monetary policy shocks.

Finally, analogous to the inversion process in equation (4), $X_{t}-$ the original variables of interest -- can be regressed on contemporaneous and lagged values of the structural shocks:

$$
X_{t}=\mu^{\prime \prime}+\rho(L) \eta_{t}^{M P}
$$

where $\rho(L)$ is a matrix polynomial. The estimate of $\rho(L)$, along with estimates for the structural shocks, can be used to calculate impulse response functions, forecast error decompositions, and variance decompositions in the usual ways.

Of course, this alternative approach is not without some potential pitfalls, some which it shares with the traditional VAR approach. First, as with a conventional VAR model or any other structural model, the econometrician must specify which economic variables in the Fed's reaction function contain newly-available information ( $\mathrm{X}_{1 \mathrm{t}}$ and $\mathrm{X}_{2 \mathrm{t}-1}$ above). Any important variable that is omitted from the analysis will bias the estimates of the structural shocks. In addition, as illustrated in the above example, there must be available and reliable measures of market participants' expectations for the federal-funds rate and for each relevant variable in the Fed's reaction function. Finally, as with a conventional VAR model or any other structural model, there could be simultaneity between the federal funds rate and variables that are in the Fed's reaction function. In that case, one must find additional innovations to use as instruments to estimate $\gamma$ in equation (7). This requires still more assumptions about which innovations to use as instruments and additional expectations measures in 
order to derive the required instruments.

\section{Economic Innovations}

The previous section of the paper described an alternative econometric approach to identifying monetary policy shocks and calculating their effects on economic variables. This section proceeds with the first step of that approach -- the derivation of the economic innovations using available measures of expectations, as well as lags of traditional macroeconomic variables. These innovations are contrasted with those derived from a traditional VAR model, and they are used in the next section to calculate monetary policy shocks, as well as impulse response functions for several variables with respect to a monetary policy shock.

\section{A Benchmark VAR}

In order to contrast results from the alternative approach with those from a traditional VAR, a benchmark VAR model is required. There has been a great deal of recent debate concerning the appropriate monetary policy instrument and the appropriate set of economic indicators to include in the

Federal Reserve's reaction function -- see, for example, Bernanke and Blinder (1992), Strongin (1992), Gordon and Leeper (1995), Christiano, Eichenbaum, and Evans (1994), and Brunner (1994).

Although the recent consensus appears to be that the federal funds rate best represents the Fed's operational instrument, there is little agreement on a reasonable set of economic indicators to include in the Fed's reaction function. The following set of economic variables, however, is representative of variables used in that literature, and they will serve as a benchmark for subsequent analysis:

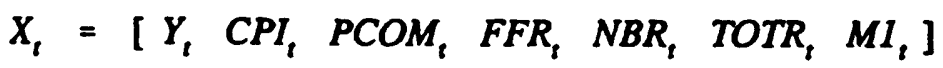

where $\mathrm{Y}$ is some measure of economic activity, $\mathrm{CPI}$ is the consumer price index, PCOM is a price index of sensitive commodities, FFR is the federal funds rate, NBR is non-borrowed reserves, TOTR 
is total reserves, and $\mathrm{Ml}$ is the $\mathrm{Ml}$ monetary aggregate. ${ }^{3}$ It is also assumed that structural shocks can be identified with a triangular decomposition based on the ordering in equation (9) and that monetary policy shocks are associated with structural shocks to the federal funds rate. This benchmark VAR model corresponds to one of the monthly modeis studied by Christiano, Eichenbaum, and Evans (1994). As they discuss, this identification scheme is somewhat defensible when using monthly data, as will be the case in this paper. ${ }^{4}$

With these assumptions, the Fed is assumed to respond to: i) contemporaneous changes in output, consumer prices, and commodity prices, ii) lagged values of all variables, and iii) a monetary policy shock:

$$
F F R_{t}=\phi+\gamma_{1} Y_{t}+\gamma_{2} C P I_{t}+\gamma_{3} P C O M_{t}+\ldots+\eta_{t}^{M P}
$$

That is, using equation (3), innovations in the federal funds rate are assumed to respond contemporaneousiy to innovations in output, consumer prices and commodity prices:

$$
u_{t}^{F F R}=\gamma_{1} u_{t}^{Y}+\gamma_{2} u_{t}^{C P I}+\gamma_{3} u_{t}^{P C O M}+\eta_{t}^{M P}
$$

As in equation (2), all VAR innovations are derived by regressing each variable in $X_{t}$ on several lags of $X_{i}$ :

$$
X_{t}=\mu^{\prime}+B(L) X_{t-1}+u_{t}
$$

As discussed in the previous section, there are at least two worrisome aspects of the decomposition of the federal funds rate in equation (11). First, neither the CPI nor most broad measures of

3 With the exception of the federal funds rate, all variables are expressed as log levels.

4 The primary purpose of this paper is to illustrate an alternative estimation strategy that incorporates expectations measures. It is not to argue the merits of any particular set of economic variables or any particular identification scheme. 
economic activity for a given period are publicly observable during that period. This means that the innovations used as regressors in equation (11) have been derived using information that is not yet available to the Fed or to other market participants. Second, all innovations have been derived by assuming a limited information set for the Federal Reserve. Even if the Fed responds only to innovations in $\mathrm{Y}, \mathrm{CPI}$, and PCOM, its expectations of those variables are likely based on a much richer information set than just lags of $\mathrm{X}_{\mathrm{t}}$. Accordingly, there is a compelling case to be made for: i) excluding $\mathrm{Y}_{\mathrm{t}-1}$ and $\mathrm{CPI}_{\mathrm{t}-1}$ from the list of regressors when calculating the innovations to $\mathrm{FFR}_{\mathrm{t}}$ and PCOM, ii) deriving innovations to $Y_{t-1}$ and $C P I_{t-1}$ rather than $Y_{t}$ and $C P I_{t}$ for use in equation (11), and iii) deriving all innovations with an assumed richer information set for the Fed by incorporating available measures of expectations. This is the focus of the next subsection of the paper.

\section{Deriving Innovations}

As shown in Table 1, there are several available options for measuring market participants' expectations of the federal funds rate, economic activity, and the consumer price index. First, there are several available market readings on the expected federal funds rate. Banks can contract to borrow or lend federal funds for 1-month intervals at the term-federal-funds rate. Thus, if markets are forward-looking, the 1-month term-federal-funds rate observed on the last day of a month (TFFR $\left.\mathrm{T}_{-1}\right)$ should be a good predictor of the month-average federal funds rate for the following month. Similarly, there are other forward-looking interest rates, including the 1-month Treasury bills rate $\left(\mathrm{TBR}_{\mathrm{t}-1}\right)$, the 1-month $\mathrm{CD}$ rate $\left(C D R_{\mathrm{t}-1}\right)$, and the 1-month Eurodollar rate $\left(\mathrm{EDR}_{\mathrm{t}-1}\right)$. Finally, if the Fed is pursuing a funds-rate targeting strategy, then the federal funds rate should reflect all economic information available to the Fed, and the lagged federal funds rate (FFR $\mathrm{T}_{\mathrm{t}-1}$ ) can also serve as a forecast of the current federal funds rate. The federal funds rate is plotted against each measures in Figure 1.

For the remaining variables, Money Market Services (MMS) provides frequent forecasts for upcoming economic releases for CPI inflation and for several monthly indicators of economic activity 
growth, including the unemployment rate (UR), retail sales (RSLS), and industrial production (IP).

Actual and forecasted values for each of these variables are shown in Figures 2 and 3.

An important question concerns whether these measures of expectations are, in fact, efficient and unbiased estimators of future values of the variables. Table 2 examines this question for the forward-looking interest rates. The table summarizes regression results based on:

$$
F F R_{t}-E\left[F F R_{t} \mid \hat{I}_{t-1}\right]=\alpha+\beta(L)\left[X_{1, t-1}^{\prime} X_{2, t-2}^{\prime}\right]+(\delta-1) E\left[F F R_{t} \mid \hat{I}_{t-1}\right]+u_{t}^{F F R}
$$

where $X_{1, t}=\left[\operatorname{PCOM}_{t} \text { FFR }_{t} \operatorname{NBR}_{t} \operatorname{TOTR}_{t} \mathrm{Ml}_{t}\right]^{\prime}$ and $X_{2, t}=\left[Y_{t} C_{t}\right]^{\prime}$, and where E[· $]$ represents a forward-looking interest rate. In particular, the table presents significance levels for four Wald tests and the $\mathrm{R}^{2}$ for each regression. The Wald tests corresponds to the following hypotheses: i) that there is not a time-invariant risk premium $(\alpha=0)$, ii) that the forward-looking interest rate is an efficient estimator $(\beta s=0)$, iii) that the forward-looking interest rate is an unbiased estimator $(\delta=1)$, and iv) that the forward-looking interest is both efficient and unbiased. An $R^{2}$ of zero would also be a general indicator that additional information (other than the forward-looking interest rate) provides no additional predictive power.

The results are generally disappointing. Although the term federal funds rate, the CD rate, and the Eurodollar rate appear to be unbiased estimators of the federal funds rate, none of the forwardlooking interest rates are efficient estimators. Other than the obvious explanation -- that banks make systematic forecast errors -- these results could be interpreted in two ways. First, the additional information could be capturing a time-varying risk premium. This argument is most plausible for the Treasury bill rate, which shows evidence of a time-invariant risk premium ( $\alpha$ not equal to zero). A second explanation might be that banks exhibit some habitat persistence, preferring not to always arbitrage away any predictable differences between current market rates and expected future federal funds rates. Still, the $R^{2} s$ in these regressions seem somewhat large to be associated with a time- 
varying risk premium or habitat persistence. In any case, while the market interest rates provide additional useful information ( $\delta=0$ is rejected in all cases), they do not by themselves provide complete information for forecasting the federal funds rate.

The ability of market participants to make accurate predictions of economic activity -- as measured by MMS forecasts -- are evaluated in Table 3 using the following regression:

$$
Z_{t}-E\left[Z_{t} \mid \hat{I}_{t-1}\right]=\alpha+\beta(L)\left[X_{1, s-1}^{\prime} X_{2, t-2}^{\prime}\right]^{\prime}+(\delta-1) E\left[Z_{t} \mid \hat{I}_{t-1}\right]+u_{t}^{2}
$$

where $Z_{1}$ corresponds to the variables listed in the first column of the table.

These results are somewhat more promising than those for the federal funds rate. First, only forecasts of retail sales appear to be inefficient. Importantly, this result is consistent with the previous conjecture that the inefficiency of the forward-looking interest rates is due to the presence of a timevarying risk premium rather than because banks make systematic forecast errors. On the other hand, MMS forecasts of two variables -- retail sales and the unemployment rate -- are biased, tending to follow the actual values down when the variable is falling and vice versa. Similarly, the joint hypothesis of efficiency and unbiasedness can be rejected at conventional significance levels for retail sales and the unemployment rate. In summary, as before, while the MMS forecasts provide additional useful information for forecasting these variables, they do not by themselves provide complete information.

Although these expectations measures appear to include important additional information on a statistical basis for forecasting these economic variables, another important question is whether these measures are important in an economic sense. This question is explored in Table 4, which presents the variances and cross-correlation matrix for several sets of innovations for the variables described above. Panel (i) lists the variances and the cross-correlation matrix for three sets of innovations to the federal funds rate. The first set was derived using the standard VAR methodology, by regressing the 
federal funds rate on 12 lags of each variable in $\mathrm{X}_{\mathrm{t}}{ }^{5}$ The second set was derived in a similar fashion, except that the first lag of UR and CPI were excluded from the regression, since they are not observable by the Fed at time $\mathrm{t}-1$. Since some information is deleted from the assumed information set, the variance of these innovations is a bit larger, although they are highly correlated with the standard VAR innovations. The third set was calculated by excluding the first lag of UR and CPI but including the term federal funds rate $\left(\mathrm{TFFR}_{\mathrm{t}-1}\right.$ ) as a regressor. Interestingly, the variance of these innovations is substantially smaller than for the other two sets of innovations, although the innovations are still somewhat correlated with the other sets.

Panels (ii) and (iii) provide similar information for innovations to the unemployment rate and to the consumer price index. It should be noted, however, that the standard VAR innovations are to $\mathrm{UR}_{\mathrm{t}}$ and $\mathrm{CPI}$, while the other two sets of innovations are to $\mathrm{UR}_{\mathrm{t}-1}$ and $\mathrm{CPI}_{t-1}$, since it is assumed in the alternative approach that the Fed responds contemporaneously to the latter innovations. There are several important features of these results. First, innovations derived using the alternative approach are essentially uncorrelated with the standard VAR innovations. Second, as before, including expectations measures substantially reduces the variance of the innovations. Still, the innovations to $\mathrm{UR}_{\mathrm{t}-1}$ and $\mathrm{CPI}_{\mathrm{t}-1}$-- derived with and with the expectations measures -- are highly correlated (.76 and .68 , respectively).

The main results of this section can be summarized as follows. First, available measures of market participants' expectations of economic variables are not by themselves sufficient for developing innovations to those variables. That is, the expectations measures are sometimes biased and inefficient estimators. Still, they provide significant additional information relative to standard VAR techniques. In all cases examined, including the expectations measures reduced the innovation variance by at least

5 All of the results presented in Table 4 were calculated using the unemployment rate as the measure of economic activity and the term federal funds rate as the expectations measure for the funds rate. Similar results were obtained with other measures. 
one-half. Finally, innovations to the federal funds rate derived using the alternative approach are only somewhat correlated with standard VAR innovations. Innovations to other macroeconomic variables are essentially uncorrelated with their standard VAR counterparts, primarily because the former are innovations to lagged values of these variables rather than contemporaneous values.

On balance, these results could have serious implications for the identification of monetary policy shocks -- which rely on correctly estimated innovations -- as well as for any conclusions to be drawn about the effects of these shocks on other macroeconomic variables. These implications are the focus of the next section of the paper.

\section{Monetary Policy Shocks}

The previous section calculated and examined the time-series properties of innovations to the federal funds rate, the $\mathrm{CPl}$, and various indicators of economic activity. These innovations were calculated using a standard VAR approach and using an alternative approach which incorporated market expectations. This section uses these innovations to derive structural shocks that will be interpreted as monetary policy shocks. The effects of these shocks on various macroeconomic variables is also examined.

\section{Policy Shocks}

As discussed earlier, innovations to the federal funds rate can be decomposed using the relationship shown in equation (10). That is, the residuals from a regression of federal funds rate innovations on innovations to economic activity, the CPI, and PCOM can be interpreted as monetary policy shocks -- the exogenous component of monetary policy. An important question that is addressed is whether monetary policy shocks derived with a standard VÂR approach have similar time-series properties to those derived with the alternative approach.

Tâble 5 presents the decomposition results, using the innovations computed in the previous 
section. Along with the parameter estimates (the $\gamma \mathrm{s}$ ), the table lists the $\mathrm{R}^{2}$ for each regression. The first three rows of the table correspond to a regressions using standard VAR innovations, where economic activity is measured by, respectively, the unemployment rate, retail sales, and industrial production. The next three rows correspond to regressions using the modified VAR approach, and the last three to regressions that use innovaations derived ưsing mâket expectations.

The important results in the table can be summarized as follows. First, as indicated in the first line of each set of regressions, the federal funds rate responds contemporaneously to new information about the unemployment rate. This is true regardless of how the innovations are calculated, although the effects are less strong for the alternative approach than for the other two methods. (This result is also robust to other expectations measures for the federal funds rate other than the term federal funds rate.)

By contrast, the federal funds rate does not respond to new information about retail sales or the CPI and only weakly to innovations in industrial production. This could be attributable to the fact that retail sales and the CPI are more volatile series than the unemployment rate, and they are also subject to many more revisions than the unemployment rate. The Fed also appears to respond contemporaneously to $\mathrm{PCOM}$, although the estimated response is not robust to how innovations are calculated. On balance, these results are consistent with Brunner (1994), who found that the unemployment rate is one of the few economic indicators that the Fed has responded to consistently in the post-war era, whereas the Fed has not responded very strongly to price developments and to other indicators of economic activity in recent years.

It is also interesting to observe that when additional information is used to calculate economic innovations (the third set of regressions), many of the regressors become less significant or even insignificant. This suggests that part of their role in the first two sets of regressions is not causal. Rather, they are serving as covariates with information that has been omitted in the standard and 
modified VAR approaches.

Finally, it is important to note that the $\mathrm{R}^{2}$ for all of the regressions in Table 5 are quite low. In other words, although the response of the federal funds rate to some of these economic indicators is statistically significant, these innovations account for only a small fraction of the variance of federal funds rate innovations. This result is also consistent with Brunner (1994), who concluded that between 85 and 100 percent of the variance of innovations to the federal funds rate can be attributed to monetary policy shocks. As a consequence, the time-series properties of the monetary policy shocks that are implied by the regressions in Table 5 are nearly the same as the properties of the innovations to the federal funds rate that are shown in Table 4.

\section{Impulse Responses}

The final task of this paper is to examine the effects of monetary policy shocks on the macroeconomy. For the VAR model, these effects can be calculated by inverting the VAR model, as shown in equation (4). For the alternative approach, impulse response functions can be calculated by regressing $W_{t}$, a variable of interest, on several lags of the estimated monetary policy shocks:

$$
W_{t}=\rho_{0}+\sum_{i=1}^{q} \rho_{1 i} W_{t-i}+\sum_{i=0}^{r} \rho_{2 i} \epsilon_{t-i}+u_{t}
$$

Note that a few lags of $\mathrm{W}_{\mathrm{t}}$ are included in the regression. It was found that these lags were necessary to stabilize the estimates of $\rho_{2 i}$, especially when $W_{t}$ is a non-stationary variable. ${ }^{6}$ It is also important to point out that this approach for computing impulse response functions is reminiscent of Barro's (1977, 1978) approach for examining the effects of unanticipated money, although the identification of the regressors (the $\varepsilon s)$ is quite different.

\footnotetext{
6 This was the case for most variables examined in this paper.
} 
Figure 4 presents impulse response functions for several macroeconomic variables, using monetary policy shocks calculated using both methodologies. The impulse responses to a VAR shock (the solid lines) were calculated using shocks derived from a VAR model that included the unemployment rate as the indicator of economic activity. That is, these impulse responses are based on the monetary policy shocks calculated in the first row of Table 5. Confidence bounds for the VAR impulse response functions are also plotted (the long-dashed lines).

Similarly, impulse response functions for the market expectations model (the short-dashed lines) were calculated using the unemployment rate as the indicator of economic activity and using expectations measures as discussed earlier. The regressions in equation (14) included three lags of the dependent variable $(q=3)$ and 24 lags of the monetary policy shocks ( $r=24)$. In addition, consistent with the previous analysis, the regressions for UR, CPI, and PCOM did not include the contemporaneous value of the monetary policy shock $\left(\varepsilon^{\mathrm{MP}}\right)$. In other words, the assumption is that these particular variables do not respond within the period to monetary policy shocks.

The results are quite surprising. Although the two sets of monetary policy shocks -- derived using a VAR model and using market expectations -- are only somewhat correlated, they have remarkably similar effects on macroeconomic variables. As shown in panel (a), both shocks have a persistent, positive effect on the unemployment rate. Panel (b) illustrates the well-known "price puzzle," the counter-intuitive result that consumer prices increase for a few months following a contractionary monetary policy shock. Evidently, the market expectations measure of the policy shock suffers from the same defect as the VAR measure. That is, as discussed by Christiano, Eichenbaum, and Evans (1994), there is some variable -- likely some measure of raw material or labor costs -- that affects contemporaneously both the federal funds rate and the CPI. As shown in panel (c), however, both sets of shocks have a small negative (but insignificant) effect on commodity price inflation.

As shown in panel (e), both sets of shocks have a strong liquidity effect on NBR, consistent 
with the effects documented by Leeper and Gordon (1992), Christiano, Eichenbaum, and Evans (1994), and Brunner (1994). The effects of a monetary policy shock are also seen (eventually) in TOTR and $M 1$, shown in panels $(f)$ and $(g)$, respectively.

\section{Conclusion}

This paper has considered an alternative econometric approach to the VAR methodology for identifying and estimating the effects of monetary policy shocks. The alternative approach incorporates available measures of market participants' expectations of economic variables in order to calculate economic innovations to those variables. In general, measures of expectations should provide important additional information relative to a standard VAR analysis, since market participants use a much richer information set to make their forecasts than the information set that is assumed in a typical VAR model. The resulting innovations are easily incorporated in a VAR-like framework, similar to the approach taken by Barro $(1977,1978)$ to examine the effects of unanticipated money on economic variables.

The empirical results are quite surprising. First, when expectations are incorporated, the variance of all innovations is reduced substantially. In all cases examined, the variances were reduced by at least one-half. Second, innovations to the federal funds rate using the two methodologies -using a VAR model and using market expectations -- are only somewhat correlated. Innovations to other economic variables are essentially uncorrelated. Still, monetary policy shocks derived using the two approaches are also somewhat correlated, since innovations to prices and economic activity explain only a small fraction of innovations to the federal funds rate. As a consequence, the impulse responses of economic variables to the two sets of monetary policy shocks have remarkably similar properties. 


\section{REFERENCES}

Bernanke, Ben (1986), "Alternative Explanations of the Money-Income Correlation," in Karl Brunner and Allan Meltzer, eds. Carnegie-Rochester Conference on Public Policy, Real Business Cycles, Real Exchange Rates, and Actual Policies, 25:49-100.

Bernanke, Ben and Alan Blinder (1992), "The Federal Funds Rate and the Channels of Monetary Policy Transmission," American Economic Review, 82:901-921.

Barro, Robert B. (1977). "Unanticipated Money Growth and Unemployment in the United States," American Economic Review, 67(2):101-15.

Barro, Robert B. (1978). "Unanticipated Money, Output and the Price Level in the United States," Journal of Political Economy, 86(4):549-80.

Blanchard, Olivier, and Danny Quah (1989), "The Dynamic Effects of Aggregate Demand and Supply Disturbances," American Economic Review, 79:655-673.

Brunner, Allan D. (1994), "The Federal Funds Rate and the Implementation of Monetary Policy: Estimating the Federal Reserve's Reaction Function," International Finance Discussion Papers, No. 466, Board of Governors of the Federal Reserve System, Washington, D.C.

Christiano, Lawrence J. and Martin Eichenbaum (1992), "Liquidity Effects, Monetary Policy and the Business Cycle," American Economic Review, 82:346-53.

Christiano, Lawrence J., Martin Eichenbaum, and Charles L. Evans (1994), "Identification and the Effects of Monetary Policy Shocks," Federal Reserve Bank of Chicago Working Paper 94-7.

Gordon, David B. and Eric M. Leeper (1993), "The Dynamic Impacts of Monetary Policy: An Exercise in Tentative Identification," Federal Reserve Bank of Atlanta Working Paper Series, Working Paper 93-5.

Leeper, Eric M. and David B. Gordon (1992). "In Search of the Liquidity Effect," Journal of Monetary Economics, 29:341-69.

Sims, Christopher A. (1980). "Macroeconomics and Reality," Econometrica, 48:1-48.

Sims, Christopher (1986), "Are Forecasting Models Usable for Policy Analysis?" Quarterly Review, Federal Reserve Bank of Minneapolis, Winter:xxx-xx.

Strongin, Steve (1992), "The Identification of Monetary Policy Disturbances: Examining the Liquidity Effect," Federal Reserve Bank of Chicago Working Paper 92-27. 
Table 1. Available Monthly Measures of Market Participants' Expectations of Selected Economic Variables

\begin{tabular}{cc}
\hline \hline Economic Variable & Source(s) of Expectations \\
\hline FFR $_{\mathrm{t}}$ & TFFR $_{\mathrm{t}-1}$ \\
& TBR $_{\mathrm{t}-1}$ \\
& $\mathrm{CDR}_{\mathrm{t}-1}$ \\
& EDR $_{\mathrm{t}-1}$ \\
& FFR $_{\mathrm{t}-1}$ \\
& \\
$\mathrm{UR}_{\mathrm{t}-1}$ & Money Market Services Survey \\
$\mathrm{RSLS}_{\mathrm{t}-1}$ & Money Market Services Survey \\
$\mathrm{IP}_{\mathrm{t}-1}$ & Money Market Services Survey \\
$\mathrm{CPI}_{\mathrm{t}-1}$ & \\
& Money Market Services Survey \\
\hline
\end{tabular}


Table 2. Are "Forward-Looking" Interest Rates

Efficient and Unbiased Estimators of the Future Federal Funds Rate?

(based on 179 monthly observations from 1980 to 1994)

$$
F F R_{t}-E\left[F F R_{t} \mid \hat{I}_{t-1}\right]=\alpha+\beta(L)\left[X_{1, t-1}^{\prime} X_{2, t-2}^{\prime}\right]+(\delta-1) E\left[F F R_{t} \mid \hat{I}_{t-1}\right]+u_{t}^{F F R}
$$

\begin{tabular}{cccccc}
\hline & \multicolumn{5}{c}{ Significance Levels } \\
\cline { 2 - 5 } Market \\
\cline { 2 - 5 } & $\alpha=0$ & $\beta s=0$ & $\delta=1$ & $\beta s=0, \delta=1$ & $\mathrm{R}^{2}$ \\
\hline TFFR $_{\mathrm{t}-1}$ & .85 & $<.01$ & .36 & $<.01$ & .41 \\
TBR $_{\mathrm{t}-1}$ & .07 & $<.01$ & $<.01$ & $<.01$ & .78 \\
CDR $_{\mathrm{t}-1}$ & .36 & $<.01$ & .84 & $<.01$ & .41 \\
EDR $_{\mathrm{t}-1}$ & .74 & $<.01$ & .31 & $<.01$ & .43 \\
FFR $_{\mathrm{t}-1}$ & .58 & $<.01$ & $<.01$ & $<.01$ & .45 \\
\hline \hline
\end{tabular}


Table 3. Are MMS Forecasts Efficient and Unbiased

Estimators of Future Economic Activity?

(based on 179 monthly observations from 1980 to 1994)

$$
Z_{t}-E\left[Z_{t} \mid \hat{I}_{t-1}\right]=\alpha+\beta(L)\left[X_{1, t-1}^{\prime} X_{2,-2}^{\prime}\right]^{\prime}+(\delta-1) E\left[Z_{t} \mid \hat{I}_{t-1}\right]+u_{t}^{Z}
$$

\begin{tabular}{cccccc}
\hline \hline & \multicolumn{5}{c}{ Significance Levels } \\
\cline { 2 - 5 } $\begin{array}{c}\text { Economic } \\
\text { Variable (Z) }\end{array}$ & $\alpha=0$ & $\beta s=0$ & $\delta=1$ & $\beta s=0, \delta=1$ & $R^{2}$ \\
\hline & .43 & .05 & .01 & .05 & .14 \\
$\mathrm{UR}_{\mathrm{t}-1}$ & .01 & .01 & $<.01$ & .26 \\
$\% \Delta \mathrm{RSLS}_{\mathrm{t}-1}$ & .90 & $<.01$ & .06 & .13 & .18 \\
$\% \Delta \mathrm{IP}_{\mathrm{t}-1}$ & .24 & .13 & .06 & .62 & .00 \\
$\% \Delta \mathrm{CPI}_{\mathrm{t}-1}$ & .82 & .61 & .89 & & \\
\hline \hline
\end{tabular}


Table 4. Are VAR Innovations Correlated with Innovations Derived Using Market Expectations?

(based on 179 monthly observations from 1980 to 1994)

i) Federal Funds Rate

\begin{tabular}{|c|c|c|c|c|c|}
\hline & \multirow{2}{*}{$\begin{array}{l}\text { Source of } \\
\text { Innovation }\end{array}$} & \multirow[b]{2}{*}{ Variance } & \multicolumn{3}{|c|}{ Correlation with: } \\
\hline & & & (1) & (2) & (3) \\
\hline 1) & Standard VAR ${ }^{a}$ & .411 & 1.00 & & \\
\hline 2) & Modified VAR ${ }^{b}$ & .503 & .95 & 1.00 & \\
\hline 3) & $\begin{array}{l}\text { Modified VAR } \\
\text { plus TFFR }_{t-1}{ }^{c}\end{array}$ & .155 & .56 & .55 & 1.00 \\
\hline
\end{tabular}

${ }^{a}$ Derived using 12 lags of $\left\{\mathrm{UR}_{\mathrm{t}} \mathrm{CPI}_{\mathrm{t}} \mathrm{PCOM}_{\mathrm{t}} \mathrm{FFR}_{\mathrm{t}}\right.$ $\mathrm{NBR}_{1}$ TOTR $\left._{\mathrm{t}} \mathrm{Ml}_{\mathrm{t}}\right\}$.

${ }^{b}$ Derived as above, excluding $\mathrm{UR}_{\mathrm{t}-1}$ and $\mathrm{CPI}_{\mathrm{t}-1}$.

${ }^{c}$ Derived as above, including expectations measure.

ii) Unemployment Rate

\begin{tabular}{llllll}
\hline \hline & & \multicolumn{3}{c}{ Correlation with: } \\
\cline { 4 - 6 } & $\begin{array}{l}\text { Source of } \\
\text { Innovation }\end{array}$ & Variance & $(1)$ & $(2)$ & (3) \\
\hline & & & & & \\
1) Standard VAR a & .024 & 1.00 & & \\
2) Modified VAR ${ }^{b}$ & .023 & .05 & 1.00 & \\
3) Modified VAR plus & & & & \\
MMS Forecast & & .013 & -.04 & .76 & 1.00 \\
\hline \hline
\end{tabular}

a Derived for $U R_{t}$ using 12 lags of $\left\{U_{t} \mathrm{CPI}_{t} \mathrm{PCOM}_{t}\right.$ FFR $_{\mathrm{t}} \mathrm{NBR}_{\mathrm{t}}$ TOTR $\left._{\mathrm{t}} \mathrm{Ml}_{\mathrm{t}}\right\}$.

b Derived for $\mathrm{UR}_{\mathrm{t}-1}$ using 12 lags of $\left\{\mathrm{UR}_{\mathrm{t}-1} \mathrm{CPI}_{\mathrm{t}-1}\right.$ PCOM $_{t}$ FFR $_{\mathrm{t}} \mathrm{NBR}_{\mathrm{t}}$ TOTR $\left._{\mathrm{t}} \mathrm{Ml}_{\mathrm{t}}\right\}$.

${ }^{c}$ Derived as above, including expectations measure. 
Table 4. (cont.) Are VAR Innovations Correlated with Innovations Derived Using Market Expectations?

(based on 179 monthly observations from 1980 to 1994)

iii) Consumer Price Index

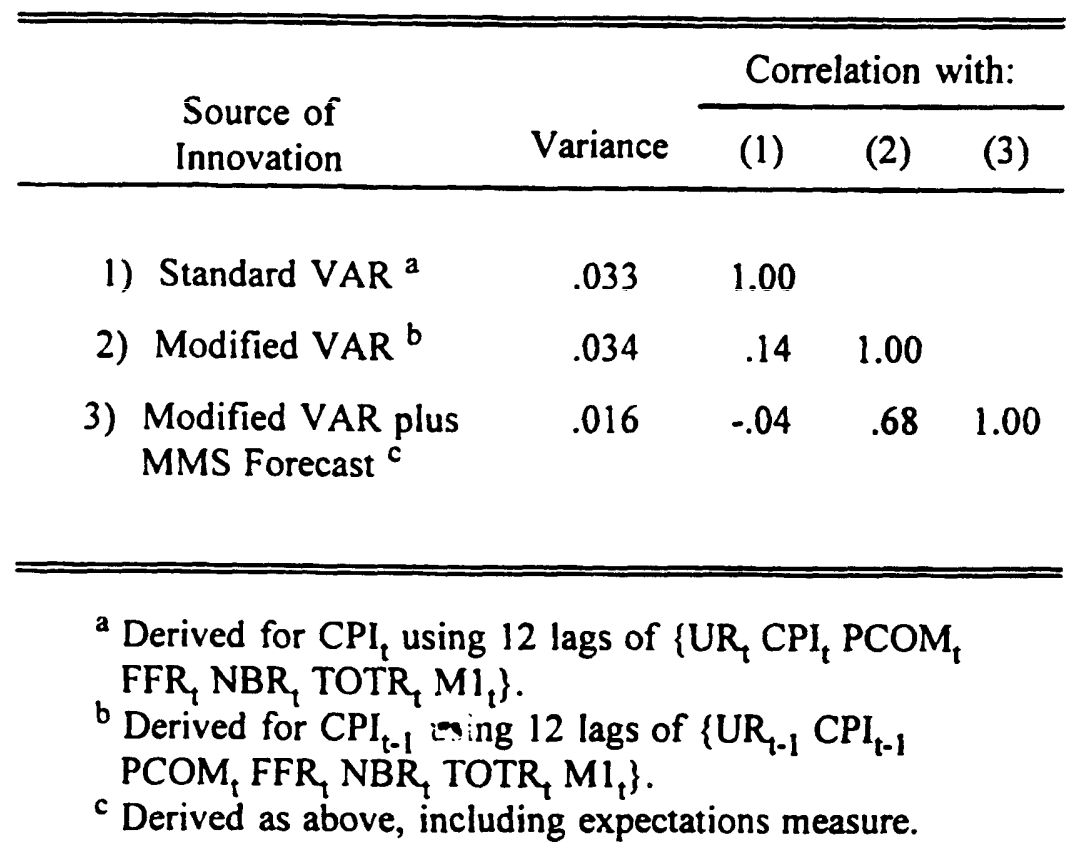


Table 5. Decomposition of FFR Innovations (based on 179 monthly observations from 1980 to 1994)

$$
u_{i}^{F F R}=\gamma_{1} u_{i}^{Y}+\gamma_{2} u_{i}^{C P I}+\gamma_{3} u_{i}^{P C O M}+\eta_{i}^{M P}
$$

\begin{tabular}{|c|c|c|c|c|}
\hline \multirow{2}{*}{$\begin{array}{l}\text { Source of } \\
\text { Innovation }\end{array}$} & \multicolumn{3}{|c|}{ Parameter Estimates } & \multirow[b]{2}{*}{$\mathrm{R}^{2}$} \\
\hline & $\gamma_{1}$ & $\gamma_{2}$ & $\gamma_{3}$ & \\
\hline
\end{tabular}

1) Standard VAR

$\begin{array}{lcccc}\text { Y=UR } & -.51^{* * *} & -.18 & .91^{* *} & .06 \\ Y=\text { RSLS } & .00 & -.14 & .72^{* *} & .02 \\ Y=\text { IP } & .12^{*} & -.11 & .64^{* *} & .04\end{array}$

2) Modified VAR ${ }^{b}$

$\begin{array}{lcccc}Y=\text { UR } & -.84^{* * *} & .02 & 1.07^{* *} & .10 \\ Y=\text { RSLS } & .01 & .12 & .80^{* *} & .02 \\ Y=\text { IP } & .10^{*} & .12 & .84^{* *} & .04\end{array}$

3) Modified VAR plus

Expectations ${ }^{c}$

$\begin{array}{lcccc}\text { Y=UR } & -.43^{*} & -.03 & .10 & .01 \\ Y=R S L S & .05 & -.03 & -.05 & .00 \\ Y=I P & .00 & -.10 & .02 & .00\end{array}$

a Derived using 12 lags of $X_{t}=\left\{Y_{t} C P I_{t}\right.$ PCOM $_{t}$ FFR $_{t}$ NBR $\bar{R}_{t}$ TOTR $\left._{t} M_{t}\right\}$.

b See "b" table notes in Figure 4.

${ }^{c}$ Derived as above, including $\mathrm{TFFR}_{\mathrm{t}-1}$ or MMS expectations measure.

"** Significant at the $1 \%$ level.

** Significant at the $5 \%$ leve!.

* Significant at the $10 \%$ level. 
Figure 1. The Federal Funds Rate and Forward-Looking Interest Rates
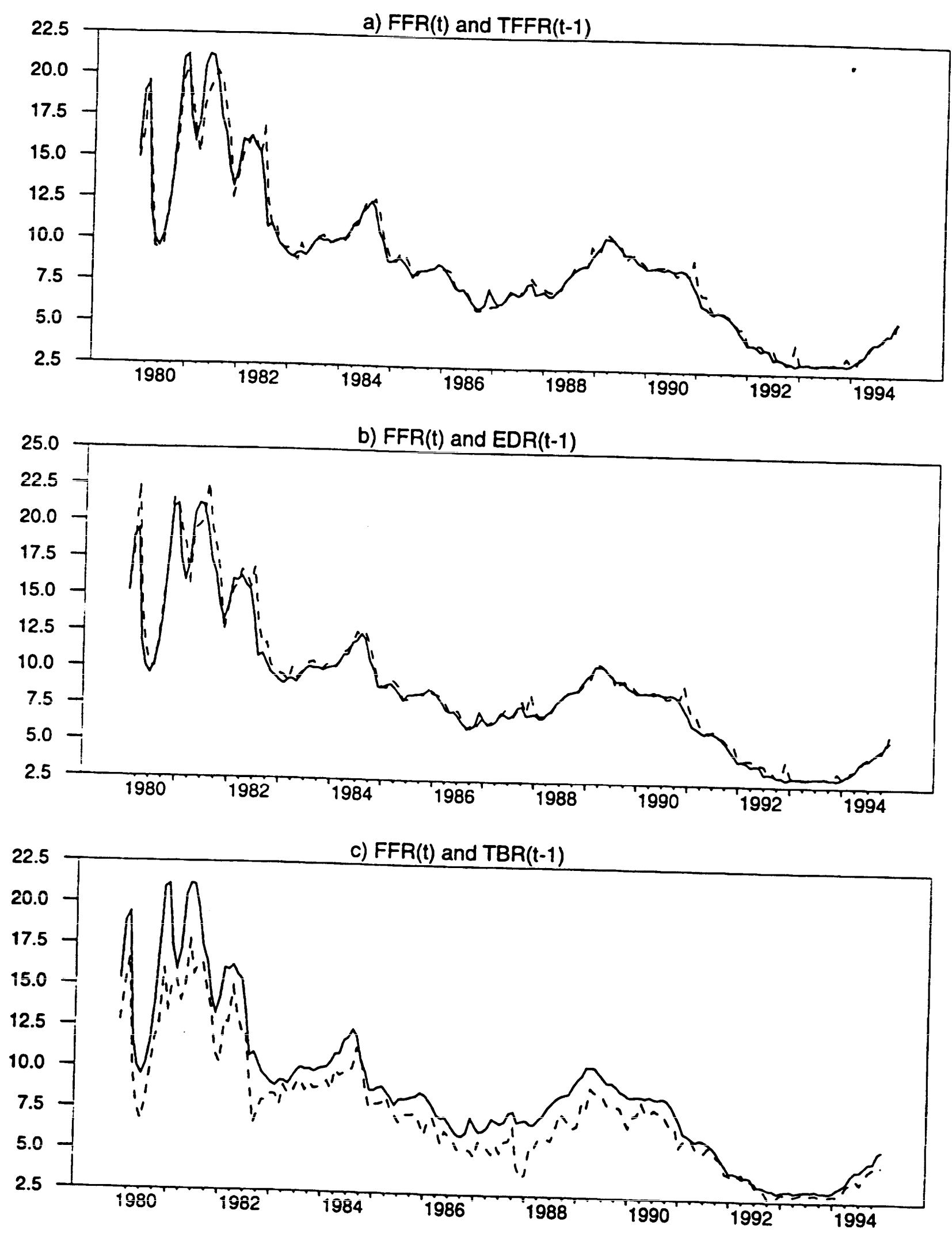
Figure 1 (cont). The Federal Funds Rate and Forward-Looking Interest Rates
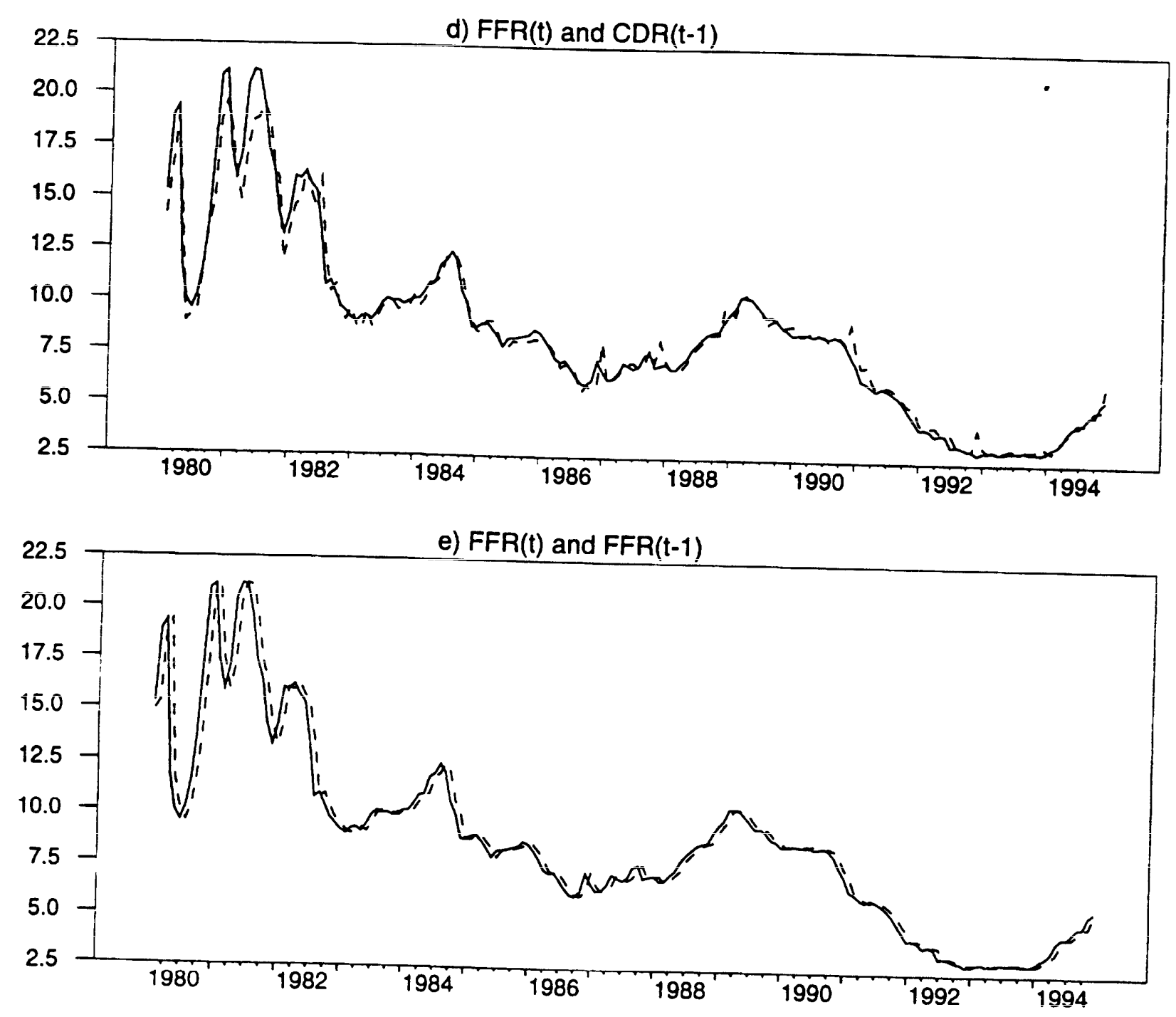
Figure 2. Actual and MMS Forecasts of Economic Growth
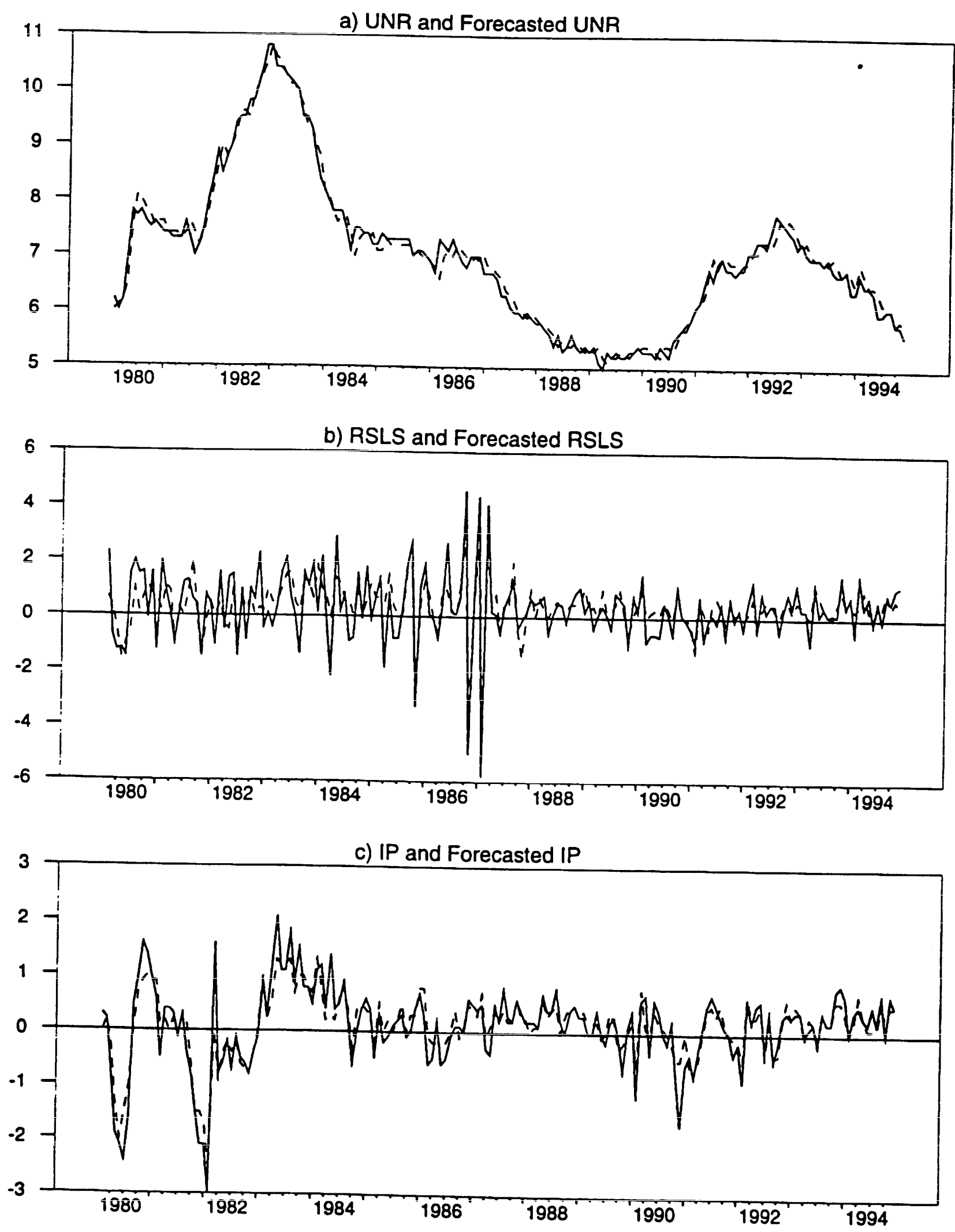
Figure 3. Actual and MMS Forecasts of CPI Inflation

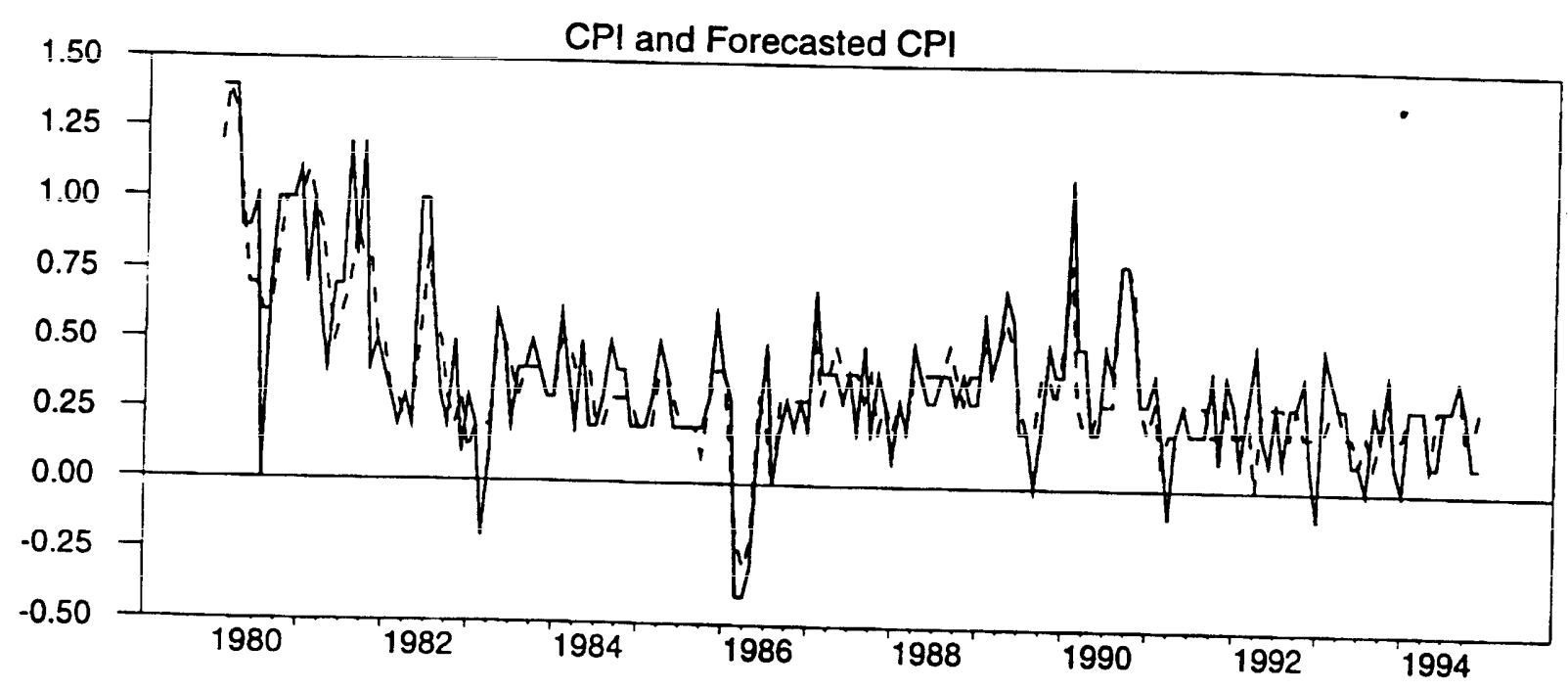


Figure 4. Responses to a Monetary Policy Shock

$$
\left(V A R=\_E X P=\ldots-\text { _ }\right)
$$
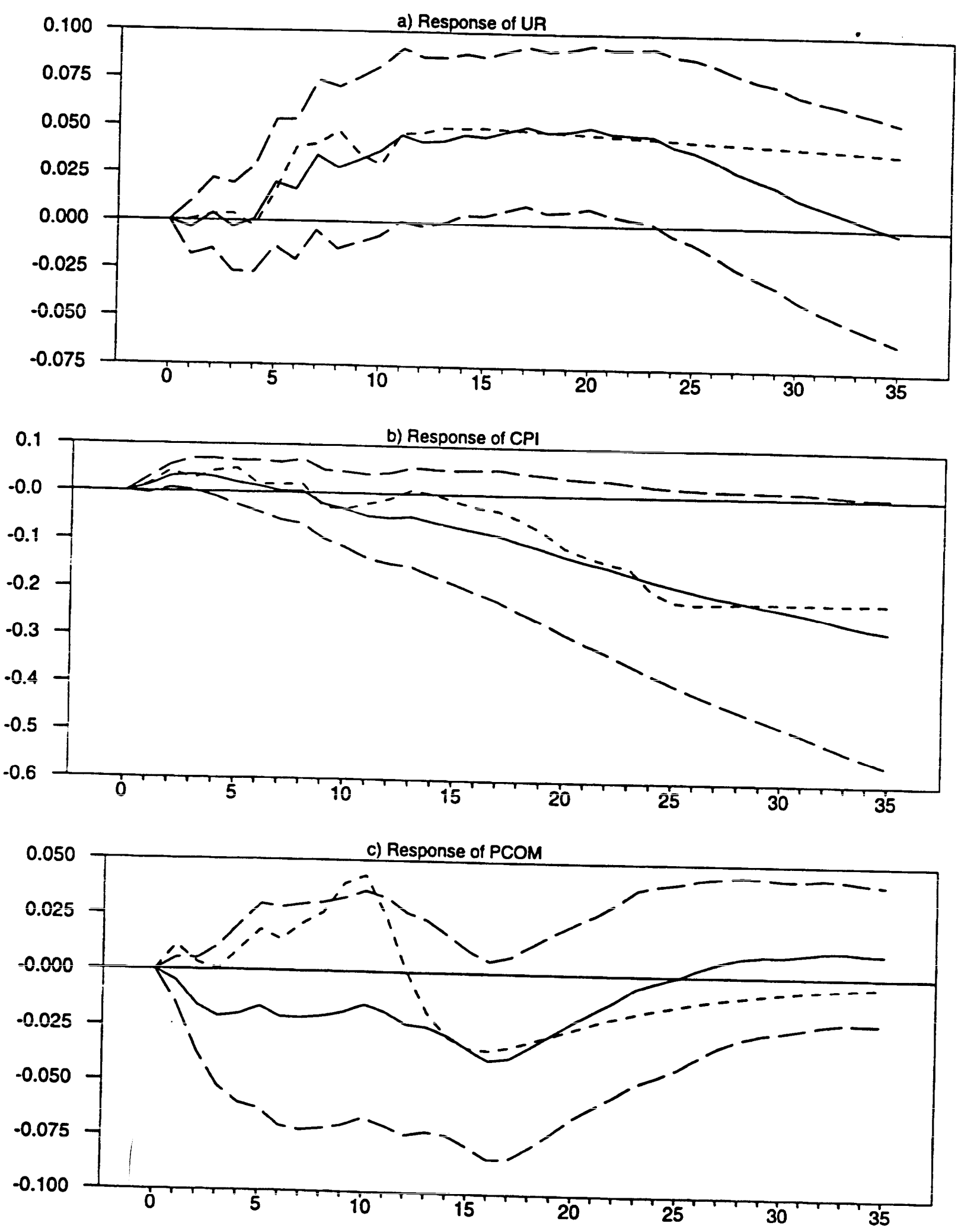
Figure 4 (cont). Responses to a Monetary Policy Shock

Figure 4 (cont). Responses to a Monetary Policy Shock

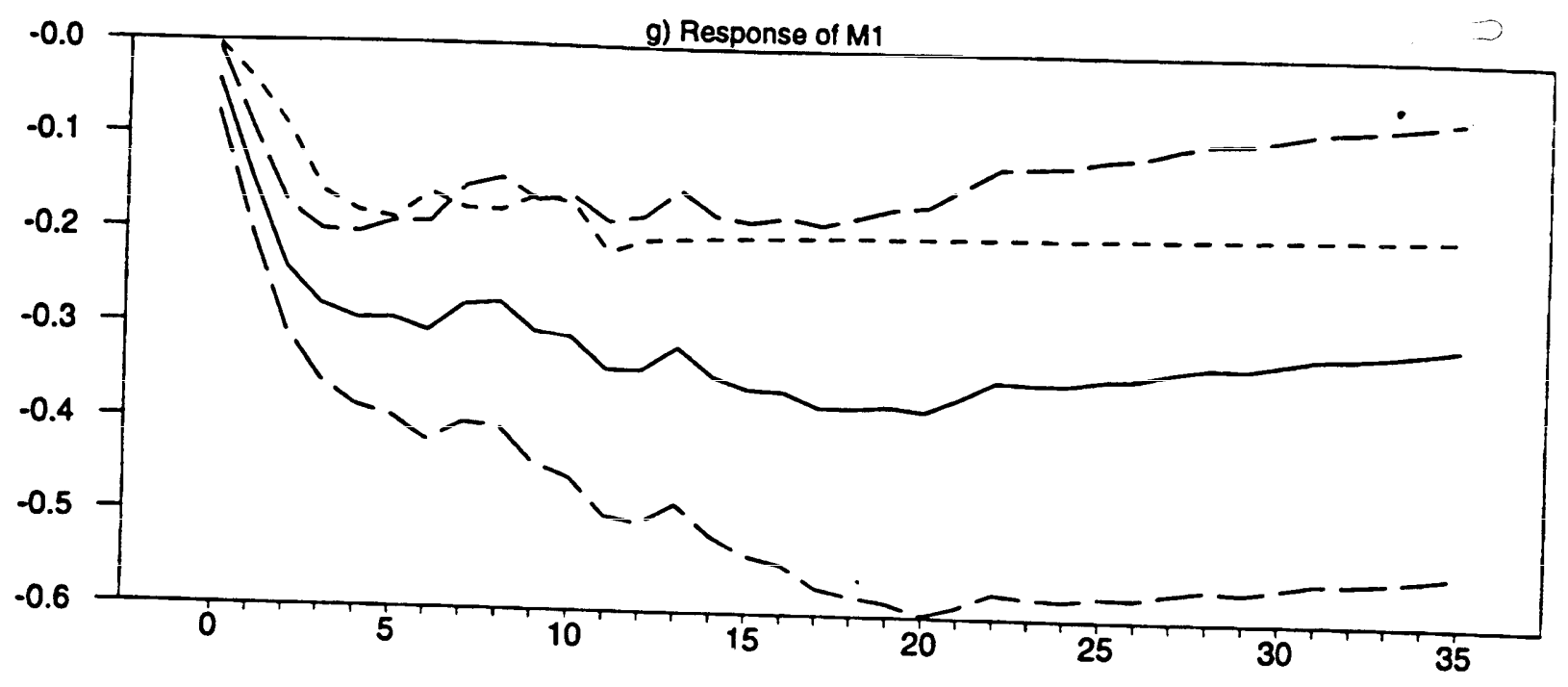




\section{International Finance Discussion Papers}

IFDP

Number
Titles

Author(s)

1996

Using Measures of Expectations to Identify the Effects of a Monetary Policy Shock

$536 \quad$ Regime Switching in the Dynamic Relationship between the Federal Funds Rate and Innovations in Nonborrowed Reserves

535 The Risks and Implications of External Financial Shocks: Lessons from Mexico

534 Currency Crashes in Emerging Markets: An Empirical Treatment

533 Regional Patterns in the Law of One Price: The Roles of Geography vs. Currencies

\section{5}

532 Aggregate Productivity and the Productivity of Aggregates

531 A Century of Trade Elasticities for Canada, Japan, and the United States

$530 \quad$ Modelling Inflation in Australia

Hyperinflation and Stabilisation: Cagan Revisited

On the Inverse of the Covariance Matrix in Portfolio Analysis

International Comparisons of the Levels of Unit Labor Costs in Manufacturing

Uncertainty, Instrument Choice, and the Uniqueness of Nash Equilibrium: Microeconomic and Macroeconomic Examples

Allan D. Brunner

Chan Huh

Edwin M. Truman

Jeffrey A. Frankel Andrew K. Rose

Charles Engel

John H. Rogers

Susanto Basu John G. Fernald

Jaime Marquez

Gordon de Brouwer Neil R. Ericsson

Marcus Miller Lei Zhang

Guy V.G. Stevens

Peter Hooper Elizabeth Vrankovich

Dale W. Henderson Ning S. Zhu

\footnotetext{
Please address requests for copies to International Finance Discussion Papers, Division of International Finance, Stop 24, Board of Governors of the Federal Reserve System, Washington, DC 20551.
} 


\section{International Finance Discussion Papers}

IFDP

Number

Titles

Author(s)

1995

525 Targeting Inflation in the 1990s: Recent Challenges

524 Economic Development and Intergenerational

Economic Mobility

523 Human Capital Accumulation, Fertility and

Growth: Â Re-Ânalysis

522 Excess Returns and Risk at the Long End of the Treasury Market: An EGARCH-M Approach

521 The Money Transmission Mechanism in Mexico

520 When is Monetary Policy Effective?

519 Central Bank Independence, Inflation and Growth in Transition Economies

Richard T. Freeman Jonathan L. Willis

Murat F. Iyigun

Murat F. Iyigun

Allan D. Brunner

David P. Simon

Martina Copelman

Alejandro M. Werner

John Ammer

Allan D. Brunner

Prakash Loungani

Nathan Sheets

518 Alternative Approaches to Real Exchange Rates and Real Interest Rates: Three Up and Three Down

517 Product market competition and the impact of price uncertainty on investment: some evidence from U.S. manufacturing industries

Hali J. Edison

William R. Melick

Vivek Ghosal

Prakash Loungani

$516 \quad$ Block Distributed Methods for Solving

Jon Faust

Multi-country Econometric Models

Ralph Tryon

515 Supply-side sources of inflation: evidence from OECD countries

Prakash Loungani Phillip Swagel

514 Capital Flight from the Countries in Transition: Some Theory and Empirical Evidence

Nathan Sheets

513 Bank Lending and Economic Activity in Japan: Did "Financial Factors" Contribute to the Recent Downturn?

Allan D. Brunner Steven B. Kamin

512 Evidence on Nominal Wage Rigidity From a Panel of U.S. Manufacturing Industries

Vivek Ghosal

Prakash Loungani 